Few ethical issues seem to arouse the passion generated by discussions of whether or when evaluators should be advocates, adversaries, or neutral in light of the social goals that programs seek to achieve. The arguments for and against evaluation advocacy are examined in terms of the American Evaluation Association's "Guiding Principles for Evaluators," more recent statements on advocacy and neutrality, and one aspect of practice: "closeness" to intended beneficiaries. The conclusion? It is time for a revised definition of Guiding Principle $C$ (Integrity/Honesiy), one that more effectively reflects our common ground and permits better articulation of standards.

\title{
The Ethics of Evaluation Neutrality and Advocacy
}

\section{Lois-ellin Datta}

Violence against clinics and medical personnel performing abortions has increased. The federal government has increased the penalties against the perpetrators and also has taken other measures. An evaluation team gathers to assess the effectiveness of these measures. One member of the team, like many others in this nation, is strongly "pro-life," believing that under the Nuremberg and other rulings, any action is justified in preventing what this person regards as the slaughter of innocents. This team member sees the government as protecting "murderers," believing the general welfare and public good demand closure of the clinics. Another team member, like many others in this nation, is strongly "prochoice," believing that law and ethics give a woman control over her own body and regarding violence against the clinics and medical personnel as criminal, not heroic. To this team member, ensuring the general welfare and public good requires the protection of clinics offering abortions. Both members call themselves evaluators. Should either of these evaluators participate in or lead the evaluation?

For this chapter, I have been asked to examine arguments for and against evaluation neutrality and advocacy. To explore these issues I have looked primarily at articles by past presidents of the American Evaluation Association and other prominent figures in our field. There is an abundance of prior words on this topic, some of which will be summarized in the next sections. Sorting through them, what struck me was not their dissimilarity but-with some exceptions-their agreement after one had worked through the definitions given of advocacy and neutrality. Nonetheless, some of the discourse on the ethics of advocacy in evaluation seems to take place as though the moral high ground had room for only one banner.

Why the passion, given the common ground? One reason may be the potential for common ground in theory to get "balkanized" in practice. A second 
reason may be whether the evaluator primarily has in mind a national study or one close to client service delivery. The explanatory power of this distinction, granted, does not always hold. Without deprecating the many ethical and moral dilemmas confronting evaluators, perhaps we could advance a bit further by examining (1) specific evaluations carried out at comparable levels in light of (2) the principles and theories put forth under different banners.

\section{Guiding Principles for Evaluators}

Our starting point is the "Guiding Principles for Evaluators" adopted by the American Evaluation Association (AEA) as "a set of principles that should guide the professional practice of evaluations, and that should inform evaluation clients and the general public about the principles they can expect to be upheld by professional evaluators" (American Evaluation Association, 1995, p. 21). There are five broad principles: systematic inquiry, competence, integrity/honesty, respect for people, and responsibilities for general and public welfare. These have been presented earlier in this volume.

All of the AEA Guiding Principles are relevant, to some degree, to the ethics of advocacy. One cannot, however, scan the principles for general guidance regarding advocacy and know exactly what actions to take. First, as intended, the principles are not standards. They do not indicate, for example, matters of practice, such as what would constitute incompetent performance or what types of education, abilities, skills, and experience would be inappropriate for different types of evaluation tasks for different evaluations. Second, it is possible for persons taking different positions on the ethics of advocacy or neutrality in evaluation to cite one or another principle as consistent with their views.

In the next sections, these apparently dissimilar positions are presented together with the AEA Guiding Principles that seem to support them, and then the positions are reexamined to identify what may be common ground that redefines the Principles. First, four definitions (Webster's, 1994):

Advocate: One who defends, vindicates, or espouses a cause by argument; upholder; defender; one who pleads for or in behalf of another

Adversary: A person or group who opposes another; opponent; foe; any enemy who fights determinedly, relentlessly, continuously

Partisan: An adherent or supporter of a person, party, or cause; biased; partial

Nonpartisan: Objective; not supporting any of the established or regular parties

\section{To Evaluate Requires Credibility: No, Evaluators Should Not Be Advocates}

There is no lack of words and deeds concerning what evaluation and the evaluator's role are about. Some could be read as indicating that the evaluator's role is about creating nonpartisan evaluations regardless of how partisan or nonpartisan the world itself may be. 
For example, Chelimsky (1997) observes:

To be listened to by various stakeholders in even an ordinary political debate requires a great deal of effort by evaluators not only to be competent and objective but to appear so. ... There are. . a great many things we can do. . not just technically, in the steps we take to make and explain our evaluative decisions, but also intellectually, in the effort we put forth to look at all sides and stakeholders in an evaluation. . . A second implication for evaluators of a political environment is the need for courage.... Speaking out in situations that may include numerous political adversaries, all with different viewpoints and axes to grind, and also insisting on the right to independence in speaking out, takes a strong stomach. ... It takes courage to refuse sponsors the answers they want to hear, to resist becoming a "member of the team," to fight inappropriate intrusion into the evaluation process ... but when courage is lost, everything is lost. [pp. 57-60; see also Cook, 1997]

This is Scriven (1997):

Distancing can be thought of as a scale on which a number of points are of particular interest. ... At one end of the scale is complete distancing, as when a program (person, policy, or whatever) is evaluated on the basis of extant data alone. At the other end is ownership or authorship of the program, usually conceded to be a poor basis for objective evaluation of it. . . Although it is better in principle to use extant data, it is often the case that one needs more, and the risks attendant on personal involvement [bias] must be undertaken. ... So-called participatory design, part of the empowerment movement, is about as sloppy as one can get, short of participatory authoring of the final report (unless that report is mainly done for educational or therapeutic purposes). . . It is sometimes suggested that the push for distance is itself an attempt to be superior, external, an attempt to play God the Judge. On the contrary, it is part of the simple and sensible human effort to get things right, to uncover and report the truth-Deciding when and to what extent to withhold those findings from those who paid for them is the "doing what's good for you, not what you asked me to do" step over the border between expertise and censorship/parenting. [pp. 484, 491]

\section{To Evaluate Is to Advocate: Yes, Evaluators Should Be Advocates}

Other work could be read as saying we are about creating partisan evaluations in an irretrievably partisan world. We should be advocates, weighing in on the side of the underdog, the oppressed, the marginalized in the fight for social justice.

Lincoln (1990) writes, "[To the positivists], only if research results were free of human values, and, therefore, free from bias, prejudice, or individual stakes could social action be taken that was neutral with respect to political partisanship.... The constructivist paradigm [has as its central focus] ... the 
presentation of multiple; holistic, competing and often conflictual realities of multiple stakeholders and research participants ... the written report should demonstrate the passion, the commitment, and the involvement of the inquirer with his or her coparticipants in the inquiry" (pp. 70-71). She further comments, "We should abandon the role of dispassionate observer in favor of the role of passionate participant" (p. 86).

Greene (1995), expanding on this thought, urges in her classic, widely cited article, "Evaluation inherently involves advocacy, so the important question becomes advocacy for whom. The most defensible answer to this question is that evaluation should advocate for the interests of the participants" (p. 1). In a related statement, Fetterman (1997) offers a nuanced argument, considering both advocacy and data credibility, that evaluation is best seen as a form of empowerment. He observes, "Empowerment evaluation has an unambiguous value orientation-it is designed to help people help themselves and improve their programs, using a form of self-evaluation and reflection. . . Advocacy, in this context, becomes a natural by-product of the self-evaluation processif the data merit it" (pp. 382-384).

And Mertens (1995):

This principle (III.D.5) concerning diversity and inclusion has implications not only at the level of identifying and respecting the viewpoints of marginalized groups, but also for the technical adequacy of what evaluators do. . . Evaluators need to reflect on how to address validity and reliability honestly in a cultural context, so as not to violate the human rights of the culturally oppressed. .. . [The emancipatory framework] . . is more appropriate to stop oppression and bring about social justice. Three characteristics [of this framework are] (1) recognition of silenced voices, ensuring that groups traditionally marginalized in society are equally "heard" during the evaluation process and formation of evaluation findings and recommendations; (2) analysis of power inequities in terms of social relationships involved in the planning, implementation, and reporting of evaluations; (3) linking evaluation results to political action. [pp. 91-92].

In the context of evaluation as advocacy, stakeholder involvement seems to mean the evaluator should take up the cause of the marginalized. The evaluator should make or support procedural, technical, and methodological decisions favoring the side of the persons directly receiving services.

\section{Some Relevant Principles and Their Implications for Anti- and Pro-Advocacy Stances}

The AEA Guiding Principles do not rule out either the anti-advocacy or proadvocacy stances, and various ones can be cited to support either position.

Against Advocacy. Several of the AEA Guiding Principles can be cited to emphasize the incompatibility of evaluation with an advocacy position as indi- 
cated in the quotes given. These are found primarily under Principle C: Integrity/Honesty. In its subparts, this principle emphasizes that evaluators should assure the honesty and integrity of the entire evaluation process through practices such as being explicit about their own (and others') interests concerning the conduct and outcome of evaluations, disclosing any roles or relationships that might pose a significant conflict of interest.

As these words are generally understood, they are inconsistent with an advocacy position. According to Webster's (1994), honest means "Honorable in principles, intentions, actions; fair; genuine or unadulterated; truthful or creditable; unadorned; just, incorruptible, trustworthy; truthful; straight forward, candid." In common understanding, as an evaluator one cannot be fair to all stakeholders and at the same time take a position of advocacy (or adversary) for or against one stakeholder group or the other. The principles tell us to be scrupulous about identifying biases, values, preconceptions favoring one outcome or another that may be held so strongly the evaluator could find it difficult to be fair, incorruptible, just, trustworthy. These threats to fairness specifically and explicitly included political stances. That is, the principles assume that evaluators have biases, prejudices, values, opinions. They require us, however, to be ever mindful of how our values may affect our conduct of the evaluation - and to disqualify ourselves from a particular study if we cannot be balanced, fair, just, incorruptible.

Different organizations use slightly different terms for the same idea. The U.S. General Accounting Office (1997) speaks of "impairments" in one's ability to be fair and just. These impairments can come not only from financial and career interests, but also from values, attitudes, and political views. However phrased, and with appreciation for the nuances of phrasing, the evaluator cannot, this principle makes clear, take sides. This is quite different from reporting findings that may favor the interests of one party or another. Rather, it means conducting the evaluation so that the findings are not slanted beginning, middle, and end by the evaluator's own passions. By this principle, the evaluator must forego balancing perceived inequities with a thumb giving greater weight to the scales of the oppressed.

Considering this reading of Principle $\mathrm{C}$, neither the pro-life nor the prochoice evaluator should be on the evaluation team. Their political positions seem so deeply held as to be considered an impairment to a fair, just, trustworthy evaluation.

For Advocacy. Another principle, however, could be read as permitting and perhaps encouraging advocacy in evaluation. Principle E considers responsibility for the general and public welfare. It explicitly states "evaluators have obligations that encompass the public interest and general good ... clear threats to the public good should never be ignored in any evaluation. Because the public interest and good are rarely the same as the interests of any particular group . . . evaluators will usually have to go beyond an analysis of particular stakeholder interests when considering the welfare of society as a whole" (American Evaluation Association, 1995, pp. 25-26). 
A common language reading of this principle requires evaluators to be ever conscious of the public good and general welfare. But the guidelines do not indicate what view of the general welfare and public good is considered: What is stated in law? By currently elected officials? By majority opinion? By the views of whatever group seems most disenfranchised by whatever indicators? By the evaluator's own perception of social justice? As Rossi (1995), discussing this principle, points out, ". . .what is the public good is the bone of contention among political parties, political ideologies, and even world religions" (p. 57). It seems as though evaluators can select any definition of the public good they choose.

What are the implications of this position for the hypothetical abortion clinics' evaluation? Considering this reading of Principle E, depending on your point of view, either the pro-life or the pro-choice evaluator should serve on the team but not both. Moreover, any evaluators who have not thought through what the common good and general welfare mean on this issue (that is, on abortion) should reach a position as part of their responsibility.

It seems noteworthy that the basis for Principle $E$ is not a belief that evaluators are irremediably unable to be objective, but rather that we serve a higher social good beyond serving those in charge and the proximal and intermediate stakeholders, such as staff and participants of a particular program. To do only the bidding of those paying for the evaluation is seen as making evaluation little more than market research. Although responsible to our clients, whether internal or external, we are equally responsible, in light of this principle, for considering the general good and public welfare.

Exactly what evaluators have to do beyond "considering" is left unstated. Presumably it includes infusing all aspects of the evaluation with the representation of the ultimate stakeholder-the public good as understood by the evaluator-in the same way one would a more proximal stakeholder.

\section{Common Ground}

This brief analysis illustrates what many other evaluators have already noted (see, for example, Rossi, 1995). The principles apparently can be cited in support of neutrality or advocacy in evaluation. It is therefore not to the AEA Guiding Principles as stated that evaluators might look for standards of conduct in specific cases or for a reconciliation, if this is possible, between apparently irreconcilable views.

The ambiguity of the AEA Guiding Principles is consistent with the intentional difference between the general guidance of principles and the operational guidance of standards. Rossi (1995) commented: "The membership of AEA is divided on a number of critical and substantive technical issues. A strongly worded set of standards might easily sunder the weak bonds that bind us together and nullify the compromises that make AEA possible" (p. 56).

The principles developed between 1992 and 1994 were intended as part of continuing discussions on ethical issues. They served us well then, in offer- 
ing an ecumenical framework for robust discourse on ethics. Seven years later, however, the principles may need refreshing in order to reflect new approaches, such as emergent realism (Henry, Julnes, and Mark, 1998), and to guide practice. Indeed, some common ground may be present in the values shared by various perspectives on the ethics of evaluation advocacy and neutrality. That is, by examining possible common denominators in recent commentaries on these issues, we may get back to a sense of how to balance apparently competing principles.

Two striking common denominators are the value placed on fairness and faithfulness to all stakeholders and on respecting deeply the dignity of all stakeholders and their right to be heard. A series of recent articles by leaders in our field, such as Lincoln, House, and Greene, gives a window on contemporary definitions of advocacy in evaluation.

This is Lincoln (Ryan, Greene, Lincoln, Mathison, and Mertens, 1998):

We operate from profound social commitments which honor all stakeholders groups' views and perspectives, whether or not we happen to agree with those views. . . . We speak of "advocacy" as if it meant we go into an evaluation determined to take sides, and that would mean typically, "against" the program managers, administrators, funders, or other critical individuals. When I talk about advocacy, I don't mean taking sides in that more specific sense. What I mean rather refers to becoming an advocate for pluralism, for many voices to feed into the evaluation. .. . What I am advocating for is less a particular individual or group than a position which insists that all stakeholders be identified and solicited for their constructions of the strengths and weaknesses of the program. [pp. 102, 108]

A similar idea was expressed vividly in her discussion (1990) of the need to "express multiple, socially constructed, and often conflicting realities. The latter we termed fairness, and judgments were made on the achievement of this criterion in much the same way that labor negotiators and mediators determine fairness in bargaining sessions" (p. 72).

This is House and Howe (1998):

We think the framework [of a Chelimsky study] must be something like this: Include conflicting values and stakeholder groups in the study. Make sure all major views are sufficiently included and represented. Bring conflicting views together so there can be deliberation and dialogue about them among the relevant parties. Make sure there is sufficient room for dialogue to resolve conflicting claims, but also to help the policy makers and media resolve these claims by sorting through the good and bad information. ... Is this advocacy on the part of the evaluators? We would say no, even though their work is heavily value laden and incorporates judgment. It is not advocacy, such as taking [one side or the other] at the beginning of the study and championing only one side or another. ... We suggest three criteria for evaluations to be properly balanced. ... 
First the study should be inclusive so as to represent all relevant views, interests, values and stakeholders. ... Second, there should be sufficient dialogue with the relevant groups so that the views are properly and authentically represented. ... . Third, there should be sufficient deliberation to arrive at proper findings. [pp. 234-245]

This is Greene (Ryan, et al., 1998):

Except in unusual circumstances, I do not believe that evaluators should advocate for the program being evaluated. Such advocacy compromises the perceived credibility and thus the persuasiveness of the evaluative claims ... what evaluators should ... advocate for is their own value commitment. ... In participatory evaluation, this value commitment is to democratic pluralism, to broadening the policy conversation to include all legitimate perspectives and voices, and to full and fair stakeholder participation in policy and program decision making ... the participatory evaluator needs to get in close to the program.... But this closeness should not be misconstrued as program partisanship. That is, participatory evaluators do advocate, not for a particular program, but rather for an open, inclusive, engaged conversation among stakeholders about the merit and worth of their program ... of fairly and fully representing all legitimate interests and concerns in an evaluation. [pp. 109, 111]

\section{Reframing the Discussion}

Neutral: A person or group not taking part in a controversy; unaligned with one side or another in a controversy; of no particular kind or characteristic; indefinite

Impartial: Fair, just

With these definitions (Webster's, 1994), a shared theme among the evaluators cited here is impartiality-the sense of fairness and justice. Neutrality, which might initially seem similar, is too passive, connoting a sort of withdrawal from the storms and complexities of the world. Passivity does not seem to me either characteristic of, or common ground for, our field. This review, then, suggests

- Diverse evaluators agree that the evaluator should not be an advocate (or presumably, an adversary) of a specific program in the sense of taking sides, of a preconceived position of support (or destruction).

- There is agreement that the evaluator should be an advocate for making sure that as many relevant cards as possible get laid on the table, face up, with the values (worth, merit) showing.

- There is agreement that the evaluator must be aware of how less powerful voices or unpopular views, positions, information can get silenced and make special efforts to ensure that these voices (data, view, information) get heard. 
Therefore, it may be helpful to reframe the discussions in terms of impartiality or fairness. No evaluation approach of which I know would countenance (1) deliberately ignoring program theories leading to different expectations about what should be studied or measured, or what results to look for, (2) deliberately selecting measures or questions to favor one side over another, (3) deliberately misquoting what an interviewee said, (4) deliberately creating data out of the whole cloth to prove a point, (5) deliberately going from the reams of raw data to conclusions by a sneaky path supporting one side over another, (6) deliberately failing to listen to the views of all parties with conflicting perspectives, (7) deliberately suppressing information that did not support the evaluator's own values or the results the evaluator wished to obtain, (8) deliberately using words that cumulatively skew the report to one side or the other, or (9) deliberately presenting complex, nuanced findings in a simplistic way to favor one position over another (Datta, 1997). Perhaps these points are a start toward expressing standards in this area with which many evaluators could agree.

This is not to say that we may not inadvertently in practice-through methodological limitations, ignorance of how our own views and language create subtle biases, or failure to use strategies for achieving fair and faithful evaluations-do all of the above or more. Rather, it is to say that as I read recent efforts to articulate what we mean, I find that we seek balance and want fairness, like a mighty river, to pour down.

\section{QED? No, Dilemmas Will Remain in Application to Practice}

Principles are not standards on how to be fair and just in practice. What principles mean in practice is likely to require continued reexamination and reinterpretation as experience grows, evaluation theories develop, and new technologies arise. For example, to some evaluators, such as Greene and Mertens, closeness and inclusion are essential. The evaluator models, by how the evaluation itself is done, ideals of empowerment, demarginalization of the disenfranchised and oppressed, and in so doing reaps many evaluation benefits such as greater authenticity, better balance, greater fairness, "natural" evaluation utilization. Since truth lies in the eye of the beholder, one logically gets as many beholders as possible.

To others, such as Scriven (1997), opinions and self-interest lie in the eye of the involved stakeholders, albeit experienced by them as truth. Closeness is to be avoided, risking as it does co-option and bias. Also to be avoided is being impartial on an issue during working hours but an adversary or advocate on the same issue when the meter isn't running. Inclusion of relevant, but unpopular or silenced views, to such evaluators is as crucial to evaluation as it is to those encouraging closeness. The techniques for achieving such inclusion are not seen as requiring sitting around a table, as it were, with the evaluator as moderator when decisions are made about design, measures, analyses, and 
reports. Rather, the techniques include using extant data and relying on performance data rather than staff interviews, and where such interviews are essential, being sure they involve prestructuring based on other data and are conducted by well-trained, well-supervised interviewers. Other approaches include goal-free methods, heavy interviewing with consumers and other stakeholders, and in all of this, applying quality control procedures such as audiotape backups.. Parenthetically, a fine example of an evaluation using such approaches in a responsive evaluation framework is now available (Stake, Davis, and Guynn, 1997).

Chelimsky (1997) is pragmatic about methods for achieving inclusiveness. Though considerably less daunted than Scriven about being captured, subdued, or co-opted by sitting down with stakeholders, she would be highly on her guard against efforts to coerce evaluators or otherwise place them in an advocacy or adversary position. (For example, being set up as a Congressional pit-bull chomping on a possibly effective but out-of-favor program such as WIC would be as threatening to the GAO's independence and credibility as being cast as a shill for a possibly ineffective but popular program such as chemical warfare.)

Are Greene and Mertens talking about different types of programs than Scriven and Chelimsky, and thus the apparent disagreements are a case of "It depends"? Evaluators vary in the ease of public access to evaluations they have completed, or in how closely anchored their discussions of advocacy and neutrality are in specific work. It seems likely that positions recommending closeness and inclusiveness are more feasible with fairly small-scale evaluations, perhaps on local or state levels. For example, one could bring out all stakeholders' voices fairly in a small program, such as a local Hospice Center, an individual school, or even a county-wide recycling program.

In contrast, although it is easy to envision inclusiveness in a national evaluation, it is more difficult to imagine one-on-one closeness. As an example, the first issue of the new Head Start journal aimed at promoting researcherevaluator and practitioner dialogue focuses on stakeholder collaboration and participation, but includes examples only from small studies, not the many national evaluations. However, some federal agencies now are writing Requests for Proposals (RFPs) consistent with empowerment and participatory views (such as the Bureau of Indian Affairs), so in the future, we may be able to see more empirically the transportability of the inclusive, close, participatory approach.

Personally, I would like to read, in full, an evaluation someone has completed (several, if possible) as a way of seeing what difference the principles make in practice and where, if any place, "it depends." We might be somewhat farther along if such evaluations were easily available as companion pieces to the more theoretical articles. House (1995) wisely wrote, "It is difficult to write intelligently about ethics and values. One reason is that ethical problems are manifested only in particular concrete cases and endorsement of general principles sometimes seems platitudinous or irrelevant. Ethical concerns become 
interesting only in conflicted cases" (p. 27). The AEA conference sessions on ethical questions and how various evaluators would address them (Morris, 1997; Nelkin, 1995) as well as the "Ethical Challenges" series in the American Journal of Evaluation represent exceptionally valuable means to this good end, as are reports such as Bell (1997) and Bickman (1996).

In a Great State, the legislature decides to go with charter schools and vouchers, so parents can send their child to the school of their choice: public, private, parochial. The stated intents are to improve student learning, improve the quality of all education, improve public confidence in and support of education, and equalize the playing field by ethnicity and family income in opportunities to learn. An evaluation team is asked to judge the merit, worth, and value of the program as implemented in achieving the benefits sought. One member of the team is strongly pro-choice, believing that social justice and equity require giving charter schools and vouchers a chance. Another member of the team is strongly anti-choice, believing that the best way to improve public education is to improve public education and that the school choice program will drain brains and money from already beleaguered public schools.

Should either of these evaluators participate in the study? My answer is that in a study such as this and the abortion clinic scenario that began this chapter, one way - but not the only way-of ensuring balance, fairness, and a less corruptible evaluation is that the team include both evaluators (see also Bell, 1997; Datta, 1997).

The team as a whole should make clear to the school board and all stakeholders their diversity of beliefs, how their differences may affect and improve the evaluation, and what else they will do to be in compliance with Principle $C$ (revised): Evaluators should be impartial, taking steps to promote the fairness, balance and justice of the entire evaluation process.

\section{References}

American Evaluation Association, Task Force on Guiding Principles for Evaluators. "Guiding Principles for Evaluators." In W. R. Shadish, D. L. Newman, M. A. Scheirer, and C. Wye (eds.), Guiding Principles for Evaluators. New Directions for Program Evaluation, no. 66. San Francisco: Jossey-Bass, 1995.

Bell, S. "Crafting a Non-Partisan Evaluation in a Partisan World: The Urban Institute New Federalism Evaluation." Paper presented at the American Evaluation Association Conference, San Diego, November 1997.

Bickman, L. "Implications of the Fort Bragg Evaluation." Evaluation Practice, 1996, 17, 57-74.

Chelimsky, E. "The Political Environment of Evaluation and What It Means for the Development of the Field." In E. Chelimsky and W. Shadish (eds.). Evaluation for the 21st Century: A Handbook. Thousand Oaks, Calif.: Sage, 1997.

Cook, T. D. "Lessons Learned in Evaluation Over the Past 25 Years." In E. Chelimsky and W. R. Shadish (eds.), Evaluation for the 21st Century: A Handbook. Thousand Oaks, Calif.: Sage, 1997.

Datta, L. "Crafting Non-partisan Evaluations in a Partisan World." Paper presented at the American Evaluation Association Conference, San Diego, November 1997. 
Fetterman, D. "Empowerment Evaluation and Accreditation in Higher Education." In E. Chelimsky and W. R. Shadish (eds.) Evaluation for the 21st Century: A Handbook. Thousand Oaks, Calif.: Sage, 1997.

Greene, J. C. "Evaluation as Advocacy." Evaluation Practice, 1995, 18, 25-36.

Henry, G. T., Julnes, G., and Mark, M. M. (eds.). Realist Evaluation: An Emerging Theory in Support of Practice. New Directions for Evaluation, no. 78. San Francisco: Jossey-Bass, 1998.

House, E. R., and Howe, K. R. "The Issue of Advocacy in Evaluations." American Journal of Evaluation. 1998, 19, 233-236.

House, E. R. "Principled Evaluation: A Critique of the AEA Guiding Principles." In W. R. Shadish, D. L. Newman, M. A. Scheirer, and C. Wye (eds.), New Directions for Evaluation, 66. San Francisco: Jossey-Bass, 1995.

Lincoln, Y. "The Making of a Constructivist: A Remembrance of Transformations Past." In E. Guba, The Paradigm Dialog. Thousand Oaks, Calif.: Sage, 1990.

Mertens, D. "Identifying and Respecting Differences Among Participants in Evaluation Studies." In W. R. Shadish, D. Newman, M. A. Scheirer, and C. Wye (eds.), Guiding Principles for Evaluators. New Directions for Program Evaluation, no. 66. San Francisco: JosseyBass, 1995.

Morris, M. (Chair). "What's an Evaluator to Do? Confronting Ethical Dilemmas in Practice." Session presented at the American Evaluation Association Conference, San Diego, November 1997.

Nelkin, V. S. (Chair). "Ethical Dilemmas in Evaluation." Session presented at the American Evaluation Association Conference, Vancouver, B.C., November 1995.

Rossi, P.H. "Doing Good and Getting It Right." In W. R. Shadish, D. Newman, M .A. Scheirer, and C. Wye (eds.), Guiding Principles for Evaluators. New Directions for Program Evaluation, no. 66. San Francisco: Jossey-Bass, 1995.

Ryan, K., Greene, J., Lincoln, Y., Mathison, S., and Mertens, D. M. "Advantages and Disadvantages of Using Inclusive Evaluation Approaches in Evaluation Practice." American Journal of Evaluation, 1998, 19, 101-122.

Scriven, M. "Truth and Objectivity in Evaluation." In E. Chelimsky and W. Shadish (eds.), Evaluation for the 21st Century: A Handbook. Thousand Oaks, Calil.: Sage, 1997.

Stake, R.E., Davis, R, and Guynn, S. Evaluation of Reader Focused Writing for the Veterans Benefits Administration. Champaign, Illinois: CIRCE at the University of Illinois, 1997.

United States General Accounting Office. Auditing Standards. Washington, D.C.: Author, 1997.

Webster's Encyclopedic Unabridged Dictionary of the English Language. New York: Gramercy Books, 1994.

LOIS-ELLIN DATTA, president of Datta Analysis, is a past president of the Evaluation Research Society and recipient of the Alva and Gunnar Myrdal Award for Evaluation in Government Service and of the Robert Ingel Award for Extraordinary Service to the American Evaluation Association. She has been director of research and evaluation for Project Head Start and the Children's Bureau; director for teaching, learning, and assessment at the National Institute of Education; and Director for Program Evaluation in the Human Services Area at the U.S. Government Accounting Office. 